\title{
Transgender and Gender Diverse Youth's Experiences of Gender-Related Adversity
}

\author{
Maggi A. Price ${ }^{1,2}$, Nathan L. Hollinsaid ${ }^{1,2}$, Emma J. Bokhour ${ }^{1,3}$, Colleen Johnston ${ }^{1}$, Hilary E. \\ Skov $^{4}$, Gabrielle W. Kaufman ${ }^{5}$, McKenzie Sheridan $^{6}$, and Christy Olezeski ${ }^{7}$ \\ ${ }^{1}$ School of Social Work, Boston College \\ ${ }^{2}$ Department of Psychology, Harvard University \\ ${ }^{3}$ Cambridge Health Alliance \\ ${ }^{4}$ Department of Psychology, Tulane University \\ ${ }^{5}$ Morgridge College of Education, University of Denver \\ ${ }^{6}$ Clinical Psychology Department, William James College \\ ${ }^{7}$ Yale School of Medicine
}

\begin{abstract}
Author Note
Maggi A. Price iD https://orcid.org/0000-0001-9825-6925

Nathan L. Hollinsaid iD https://orcid.org/0000-0001-8808-607X

Hilary Skov (iD https://orcid.org/0000-0002-8633-2684

Christy Olezeski iD https://orcid.org/0000-0002-2033-4054

Correspondence concerning this article should be addressed to Maggi A. Price, McGuinn Hall 126, Boston College, 275 Beacon Street, Chestnut Hill, MA 02467. Email:
\end{abstract} maggiprice1@gmail.com

Version 2 (July 27, 2021). Manuscript accepted for publication in Child and Adolescent Social Work. 


\begin{abstract}
Purpose: Transgender and gender diverse youth (TGD youth; i.e., children and adolescents who do not identify with their birth-assigned sex) face a variety of traumas and adversities, including those explicit to their gender identity and/or expression (hereafter "gender"; e.g., gender-related victimization, caregiver rejection). However, few studies or clinical assessment measures capture the full spectrum of adversities TGD youth experience. A comprehensive examination of genderand non-gender-related adversities faced by TGD youth is critical to understand their high risk for mental health problems and to inform best practices for clinical assessment and care.
\end{abstract}

Method: The present study sought to qualitatively examine gender- and non-gender-related adversities using clinical interview data from a sample of TGD youth $(N=49$; ages $11-20 ; 76 \%$ White) seeking services at a pediatric gender center. Interview data were analyzed using deductive content analysis. To support future measure development, existing measures of adversity and gender minority stress informed the analysis.

Results: Results highlighted the saliency of gender-related adversities among TGD youth, the themes of which included verbal abuse, threats or acts of physical and sexual assault, discrimination, nonaffirmation, and rejection.

Discussion: Implications for clinical assessment with TGD youth and future avenues in measure development are discussed.

Keywords: transgender, children, adolescents, trauma, adverse childhood experiences, gender minority stress 


\section{Transgender and Gender Diverse Youth's Experiences of Gender-Related Adversity}

Research consistently indicates that transgender and gender diverse (TGD) people (whose gender differs from their birth-assigned sex; Vance et al., 2014) face a disproportionately high risk for a variety of traumatic experiences explicitly or indirectly related to their gender (Valentine \& Shipherd, 2018; Wirtz et al., 2018). TGD people also report substantial exposure to traumas that may be unrelated to gender (e.g., physical neglect; Schnarrs et al., 2019). Yet, few if any studies ask participants to differentiate between traumatic experiences that are, or are not, related to their gender (for exceptions, see Bockting et al., 2013; Veale et al., 2017).

Retrospective studies with TGD adults document rates of childhood violence (e.g., abuse, bullying) ranging from 26-79\% (Hwahng \& Nuttbrock, 2014; Nemoto et al., 2011; Reisner et al., 2014, 2016), much of which is perpetrated by family members (Grossman et al., 2005; Peng et al., 2019). Likewise, TGD youth report experiencing violent victimization (e.g., physical and sexual assault) in schools, their communities, and intimate partner relationships (Goldenberg et al., 2018; Johns et al., 2019; Murchison et al., 2019; Rosenberg, 2019). Rates of polyvictimization are especially high among TGD youth; for instance, in a large national convenience sample of TGD adolescents, at least half experienced five or more forms of victimization (e.g., physical assault, intimate partner violence) over the course of a year (Sterzing et al., 2017). Notably, these traumatic experiences significantly contribute to TGD adolescents' heightened risk for mental health problems (e.g., depression, suicidality; Price-Feeney et al., 2020; Veale et al., 2017; Wilson et al., 2016).

\section{Adverse Childhood Experience (ACE) Exposure Among TGD Youth}

A much smaller research base documents TGD youth's exposure to adverse childhood experiences (ACEs), historically defined as specific traumatic events (e.g., childhood physical 
abuse) associated with poor mental and physical health outcomes (Felitti et al., 1998). ACE exposure is traditionally assessed on a 10-item measure focusing on domains of household dysfunction, abuse, and neglect (i.e., the ACEs-Questionnaire; Felitti et al., 1998). Consistent with the broader trauma literature, TGD people report substantial ACE exposure on this scale. For instance, in one study, 61\% of TGD adults reported at least 4 ACEs (Schnarrs et al., 2019). Further, both TGD adults (Schnarrs et al., 2019) and youth (Craig et al., 2020) are more likely to report ACEs (e.g., neglect, emotional abuse) when compared to cisgender lesbian, gay, and bisexual (LGB) people - a population that also experiences disproportionately high ACE exposure (i.e., relative to cisgender heterosexual people; Austin, Herrick, et al. 2016). However, the current literature on ACE exposure in TGD samples may be limited by the narrow scope of its measurement (Vance \& Rosenthal, 2018), as most research has exclusively utilized the original ACE scale (e.g., Craig et al., 2020; Schnarrs et al., 2019).

The expansion of the original ACE scale (Felitti et al., 1998) has been supported in several recent studies of novel ACE measures encompassing adversities occurring outside the home (e.g., discrimination, peer bullying; Cronholm et al., 2015; Finkelhor et al., 2015; Karatekin \& Hill, 2019; Koita et al., 2018). Such measures may more fully capture the experiences of diverse populations. For example, a measure including community-level ACEs (e.g., community violence, foster care involvement) better identified inequities in adversity exposure across several demographic characteristics (e.g., race, income) than the original measure (Cronholm et al., 2015). Likewise, a modified scale measuring ACE frequency outperformed the traditional dichotomous scale (i.e., asking whether respondents experienced a given ACE) in predicting mental health outcomes for a large LGB and TGD sample (Bond et al., 2021). Taken together, these findings suggest that a more nuanced ACE framework might be 
more appropriate for minoritized groups (i.e., people who are placed into a "minority" status reflecting historical and structural marginalization, rather than statistical underrepresentation; Benitez, 2010; Sotto-Santiago, 2019). However, to our knowledge, no studies have examined expanded ACE exposure among TGD youth. It is possible that even these improved measures might not adequately capture the complexity of adversities experienced by this population, as mounting evidence reveals that TGD people experience adversities specific to gender (Bockting et al., 2013; Parr \& Howe, 2019; Veale et al., 2017), which are not assessed in extant measures of trauma and adversity.

\section{Gender-related Adversities}

Gender minority stressors are defined as those that are unique to TGD people (i.e., not experienced by cisgender people; Meyer, 2003; Testa et al., 2015) and involve both distal (or external) experiences (e.g., discrimination in interpersonal relationships) and proximal (or internal) responses (e.g., internalized transphobia). Distal gender minority stressors encompass gender-related (1) interpersonal or institutional discrimination, including policies restricting TGD people from actualizing or expressing their gender (e.g., denied access to bathrooms or health care; Clark et al., 2018), (2) rejection, or being emotionally or physically distanced from peers or family members because of gender, (3) victimization, or being verbally, physically, or sexually abused based on gender, and (4) nonaffirmation, or ways in which others question, fail to acknowledge, or actively deny TGD youth's gender (Chang \& Chung, 2015; Testa et al., 2015). Nonaffirmation may or may not involve malicious intent and can be enacted through misgendering (i.e., misclassifying TGD people based on dominant understandings of genders and bodies; Riggs et al., 2015), deadnaming (i.e., the unwanted use of one's birth name, rather than their affirmed name; Johnson et al., 2020), and broader statements undermining one's gender 
(e.g., questioning, minimizing, and/or denying; Johnson et al., 2020; Parr \& Howe, 2019; PuliceFarrow, Brown, et al., 2017; Pulice-Farrow, Clements, et al., 2017). Studies of TGD youth have linked these gender minority stressors to negative mental health outcomes (e.g., depression, anxiety, suicidal ideation; Hidalgo et al., 2019; Johnson et al., 2020; Russell et al., 2018; Wilson et al., 2013). Though gender minority stressors have not been situated within an ACE framework, these findings suggest that they similarly impact TGD people's mental health. Accordingly, comprehensive measures of trauma and adversity for TGD youth should be designed to encompass those that are explicitly related to gender (Kroppman et al., 2021; Vance \& Rosenthal, 2018). To this end, qualitative research with TGD youth can be useful to better characterize and thus effectively measure these experiences (Creswell \& Zhang, 2009;

Stutterheim \& Ratcliffe, 2021). Addressing this gap has great potential to help social workers and other providers comprehensively assess TGD youth's mental health risks and wellbeing-a competency area lacking in social work (Austin, Craig, et al., 2016) despite important advances in the NASW Code of Ethics (National Association of Social Workers, 2017) and recent calls for increased social work training in culturally responsive and affirming care with TGD people (e.g., International Federation of Social Workers, 2014; see Breaux \& Thyer, 2021 for a review). In addition, thoroughly examining TGD youth's adversity exposure will help scholars better understand factors that drive the substantial inequities in mental health problems (e.g., suicidality) faced by this population (Becerra-Culqui et al., 2018).

\section{The Present Study}

This study aims to elucidate TGD youth's adverse experiences, with an emphasis on those specific to gender. Few studies to date have examined gender-related adversity in TGD youth qualitatively, and none to our knowledge has done so using an ACE framework to support 
future measure development. Scholars have called for an examination of the complex interplay between ACEs and gender minority stressors (Craig et al., 2020). Accordingly, we utilized both the Expanded ACEs Scale (Karatekin \& Hill, 2019) and the Gender Minority Stress and Resilience (GMSR) measure (Hidalgo et al., 2019; Testa et al., 2015) to inform a qualitative analysis of clinical interview data on trauma and adversity in a sample of TGD youth seeking gender-affirming care.

\section{Method}

\section{Participants and Procedures}

Participants were TGD youth ( $N=49$; ages 11-20) seeking gender-affirming care (i.e., services supporting TGD people's social and/or medical transition to live as their affirmed gender) at a pediatric gender clinic (see Table 1 for participant demographics). At an initial evaluation, participants completed a routine assessment battery regarding their readiness for medical gender transition services (e.g., pubertal suppression, gender-affirming hormone therapy). In line with the World Professional Association for Transgender Health's Standards of Care, these assessments included a comprehensive semi-structured clinical interview addressing topics critical to a fully-informed transition (e.g., in person or online peer support, school support, experiences in mental health therapy; Coleman et al., 2012). Assessors included psychologists and fellows in psychology or psychiatry, all of whom were trained by the clinic director, the study's last author and a licensed psychologist with expertise in gender-affirming care. During administration, assessors attempted to document participants' verbatim answers; their notes were electronically transcribed and provided to the research team for analysis.

All study procedures and documents (e.g., assents, consents) were IRB-approved. Youth assent (for participants younger than 18 years) and consent (for participants 18 years and older) 
to study participation were obtained prior to the assessment. Consistent with clinic policy, minors who assented could only participate if their caregivers also consented. Participants assented or consented both verbally and in writing according to best practices for research with TGD people (Adams et al., 2017) after being given copies of the forms to read during and after the visit. Youth were counseled that their agreement to research participation would have no impact on their access to care or the quality of care they received at the clinic. Participants were assured that if they decided to participate, all interview notes would be deidentified using a code number to replace protected health information.

\section{Qualitative Data}

Qualitative data on adversity were obtained from the aforementioned clinical interviews, which included several questions about trauma and adversity (Ehrensaft et al., 2014), consistent with best practices for gender-affirming care (Coleman et al., 2012). Specifically, participants were asked six questions about non-gender-related adversities (though in response to these questions, participants also cited gender-related experiences), including exposure to emotional, physical, and sexual abuse, community violence, life-threatening injury, serious illness, and unexpected death. Three additional questions examined adversity (e.g., peer victimization, discrimination) explicitly related to gender at home (e.g., "Are/were you ever harassed or ridiculed at home about your masculinity, femininity, or ways you express your gender?') and school (e.g., "At school, are/were you harassed or ridiculed because of your gender expression?"). Twenty additional questions elicited responses about gender- and non-gender related experiences (e.g., "How have your parents influenced your decision to present yourself as your affirmed gender in different settings?”). For a complete list of questions, see Table 2.

\section{Analysis}


We used deductive content analysis to analyze interview data, following procedures outlined by Kyngäs \& Kaakinen (2019). This permits researchers to apply existing theoretical and conceptual frameworks to new contexts or populations (Elo and Kyngäs, 2008). Principally, we sought to answer: "What gender-related adversities are TGD youth exposed to?" We defined gender-related adversity as an adverse event motivated by TGD youth's gender. Though not the main focus of our study, we also explored: "What non-gender-related adversities are TGD youth exposed to?" These questions aimed to elucidate whether adversity experienced by TGD youth is, or is not, fully captured in current ACE frameworks (e.g., Felitti et al., 1998). Our analytic approach involved the following steps: (1) codebook development through the identification of existing ACE frameworks and exploration of emerging conceptualizations of gender-related adversity and gender minority stress; (2) a multistep coding and validation process; and, (3) the reporting of results across themes (i.e., categories of related codes) and subthemes (i.e., subcategories of related codes).

\section{Codebook Development}

Per our deductive approach, a priori codes were identified by the first two authors, who comprehensively reviewed the extant literature on ACE frameworks (e.g., Cronholm et al., 2015; Felitti et al., 1998; Finkelhor et al., 2015; Karatekin \& Hill, 2019; Koita et al., 2018), TGD youth adversity exposure broadly (e.g., Johns et al., 2019; Sterzing et al., 2017), and emerging conceptualizations, studies, and measures of gender-related adversity specifically (e.g., Hidalgo et al., 2019; Johnson et al., 2020; Russell et al., 2018; Tan et al., 2020; Testa et al., 2015). Based on this review, two measures were identified as the most comprehensive measures of ACEs and gender-related adversity, respectively: Karatekin \& Hill's (2019) Expanded ACEs Scale and the Gender Minority Stress and Resilience (GMSR) measure (Hidalgo et al., 2019; Testa et al., 
2015). This review yielded a maximally inclusive yet theoretically-informed codebook of 34 codes (see Table 3 for codes and definitions) comprising adversity-related constructs mirroring the items in these measures. Our codebook thus included gender-related and non-gender-related adversities. During the coding process (described further below), coders distinguished between these two categories based on whether a participant (a) described adversity in response to a question about gender-related adversity (see "Gender related adversity questions" in Table 2) or (b) when a participant explicitly referenced their gender identity, expression, or a gender-specific experience (e.g., coming out) when describing an adversity in response to a question that did not explicitly reference gender (see additional questions in Table 2).

Expanded ACEs Scale (Karatekin \& Hill, 2019). Thirty-one codes corresponded to the 31 items of the Expanded ACEs Scale (Karatekin \& Hill, 2019). Building on the original ACEs questionnaire (Felitti et al., 1998), this extended measure assesses adversity across four domains: child maltreatment (8 codes; e.g., caregiver physical abuse or neglect), household dysfunction (4 codes; e.g., family psychopathology or substance use), community dysfunction (11 codes; e.g., witnessing physical violence or murder), and peer/sibling dysfunction or property victimization (8 codes; e.g., name-calling or physical bullying by peers). Newly incorporated items encompass exposure to caregiver and peer verbal abuse (e.g., name-calling), among others, which are not consistently conceptualized as ACEs yet well documented among TGD youth (e.g., Day et al., 2018; Grossman et al., 2005). These adversities may or may not be associated with gender, and thus we coded whether (or not) they were explicitly linked to gender by TGD youth (in their own words or in response to interview questions on gender-related experiences; for more information on coding, see "Coding and Validation Process"). As several Expanded ACEs Scale items comprehensively measure victimization (see Table 3 for examples), we used these to code both 
non-gender-related and gender-related victimization (as opposed to existing measures of gender minority stress, such as the GMSR, which probe but less exhaustively assess gender-related victimization; Testa et al., 2015). The Expanded ACEs Scale, however, does not adequately address other gender-related adversities (e.g., discrimination, rejection). Although it includes items on discrimination and social isolation, they are limited in scope. For instance, discrimination is specific to race/ethnicity, disability, sexual orientation, or immigration status, and social isolation entails prolonged loneliness but not necessarily rejection.

Gender Minority Stress and Resilience Scale (GMSR; Testa et al., 2015). To fill this potential gap, we identified 3 additional codes (see Table 3 for definitions) by combining items from 3 of the 9 subscales of the Gender Minority Stress and Resilience (GMSR) scale (Testa et al., 2015): gender-related discrimination (5 items; e.g., difficulty accessing bathrooms), rejection (6 items; e.g., distanced from caregivers or friends), and nonaffirmation (6 items; e.g., misgendering). As noted above, we did not use the GMSR gender-related victimization subscale to inform codes, as items were less comprehensive compared to those from the Expanded ACEs Scale (e.g., they did not capture community violence or distinguish between caregiver and peer verbal abuse; Karatekin \& Hill; 2019). Further, we did not consider other GMSR subscales (i.e.., internalized transphobia, pride, negative expectations for the future, nondisclosure, community connectedness) when identifying codes, as they were not germane to adversity.

\section{Coding and Validation Process}

Coders represented diverse gender identities/expressions and sexual orientations. They included three bachelor's-level and two master's-level research assistants. They were supervised by a counseling psychologist researcher (first author) with experience providing traumainformed and gender-affirming mental health care. Prior to engaging in the research process, 
they participated in a training on qualitative research methods. Before initiating analysis, researchers met for an hour-long meeting to identify and discuss potential biases related to their identities and experiences. Specifically, they acknowledged that their gender identities and racial/ethnic backgrounds, though diverse, did not fully reflect those of participants. They also discussed how their own trauma histories, including instances of gender- and other identitybased adversities, might impact their ability to code objectively. Coders also created a system wherein trigger warnings (i.e., notes cautioning that certain content may cause distress to coders who have experienced similar trauma) were documented (e.g., suicide attempt, sexual abuse). If a coder opted out of coding a specific interview due to such a warning, the interview was reassigned by the first author. After the first four interviews were coded by all team members (details below), this system was implemented for one coder who thereafter was assigned to be the second or third coder (to ensure that trigger warnings were identified by the first coder) and reassigned from any interview containing a particularly triggering type of trauma.

The unit of analysis was at the participant-level (i.e., responses to one or more interrelated interview questions), with codes applied to TGD youth's quotes. Under the first author's supervision, all five members of the coding team collectively coded four interviews across two meetings. Thereafter, all interviews were coded by at least two coders, independently validated by a third, and verified by the first (and senior) author. We employed consensus building to ensure coding reliability (Hill et al., 2005), a process viewed by many qualitative researchers as superior to assessing interrater reliability, as it prioritizes discussion and perspective-taking to reach agreement rather than simply quantifying agreement (Hill et al., 1997). Specifically, the first author presented any identified discrepancies between the codebook and individual codes during weekly team meetings, and the entire coding team discussed them 
until they came to a mutually agreed on coding decision. During these discussions, coders shared their rationale for codes, attended to potential biases, clarified codebook definitions, and revisited earlier coding decisions (for which detailed notes were maintained). In any instance of uncertainty regarding a particular coding decision (prior to the first author's examination), coders could (and frequently did) request consultation at their weekly coding meeting, and the team collectively decided on the appropriate code. This approach prioritized absolute agreement over the discussion and resolution of differences, which risks silencing diversity in perspectives (Cypress, 2017; Hill et al., 2005). For these reasons, and to avoid potential threats to trustworthiness (Lincoln \& Guba, 1986) rather than establishing or quantifying inter-coder reliability (i.e., agreement between coders), we elected to employ consensus building at all stages of the analytic process to address discrepancies in coding (Hill et al., 1997, 2005).

\section{Results}

In line with our primary and secondary research questions, we classified adversities as gender-related or non-gender-related and report results accordingly. Non-gender-related adversities comprised four themes corresponding to the four factors of the Expanded ACEs Scale (Karatekin \& Hill, 2019): (1) child maltreatment, (2) family dysfunction, (3) community dysfunction, and (4) peer/sibling dysfunction and property victimization. Such adversities are increasingly well documented among TGD people (for examples, see Bond et al., 2021; Craig et al., 2020; Schnarrs et al., 2019) and fall beyond the primary aim of our paper. As such, these findings are detailed extensively (e.g., themes, subthemes, quotes) in Table 4. Gender-related adversities were explicitly linked to gender in participants' words or based on their responses to interview questions about gender-related experiences (see questions in Table 2). They fell into five themes: (1) gender-related verbal abuse, (2) threats or acts of gender-related physical and 
sexual assault, (3) gender-related discrimination, (4) gender-related nonaffirmation, and (5) gender-related rejection. Below, we describe these themes and associated subthemes and provide representative quotes. To enhance the readability of some quotes, which assessors often recorded in short-hand or by using third-person narratives, we added the following words as necessary (provided they did not alter the quote's meaning): "I," "to," "the," “you," "and," "my," "a," "he," "she," "they," "in," "it," and "with."

\section{Gender-Related Verbal Abuse: "You're the Child Called It"}

Gender-related verbal abuse referred to name calling and other forms of verbal bullying (e.g., saying hurtful things) by others (e.g., peers, caregivers) relating to TGD youth's gender and causing emotional distress. We identified five subthemes of gender-related verbal abuse:

\section{Verbal Transphobia}

TGD youth documented instances when others used transphobic slurs (i.e., pejoratives used to demean TGD people; e.g., "tranny," "transvestite"). As described by one participant, this occurred at a same-gender school and was a source of anger and concern:

I'd rather not disclose that I'm trans because of safety reasons at my boys school. I had assholes at school. As I walked to class, a kid said, “Are you trans? So what? Oh! You're a tranny." I can usually keep my anger in check and tell other people. But, I went to the principal and told him, "If you don't stop this, I will knock the kid out."

Participants were frequently referred to as "it" or "he/she" by peers across multiple contexts (e.g., at school, at after-school programs, outside of school), as recounted by one TGD youth:

Last year, I tried to be a techie for a musical. At theatre, a guy kept harassing me and started calling me "it." He got others to call me "it." They call me "it" in the hallways. They say, "Look! It's coming!" I told the Dean of the House (at school). He said, "If they 
say one more thing, I will get involved." People outside of school call me "it." I still present how I want. If I hang out with them, I hear it. It sucks to be friends with someone who doesn't get it.

\section{Verbal Homophobia}

TGD youth were likewise exposed to homophobic slurs (i.e., negative terms based on others' perceptions of an individual's sexual orientation; e.g., "dyke," "faggot," and "gay" when used pejoratively). Participants noted, however, that this was often motivated by their gender rather than their sexual orientation. One TGD youth shared experiences of verbal homophobia when playing sports:

I was never interested in Barbies or girly toys. I did figure skating in the past, but I got bored with it. I switched to hockey in second grade. I got my hair cut this summer. People on my hockey team make fun of me and ask intrusive questions. They asked why I cut my hair. They state, "He’s gay!” My hockey coach is mean. He calls me "gay."

Another participant experienced verbal homophobia at school after supporting a TGD public figure on social media:

I was bullied in middle school because I defended Caitlyn Jenner on social media.

People started talking about me. I was called a "dyke" in the hallway. Another girl looked at me and said "faggot."

\section{Gender Expression}

Verbal abuse was also tied to TGD youth's gender expression (i.e., outward presentation of gender through physical appearance or behavior; e.g., clothing, makeup, hairstyle, 
mannerisms) and occurred in multiple settings (e.g., home, school, public). For example, this transpired when one participant wore clothing consistent with their affirmed gender in public: Last year, I was wearing a black dress in public. I was scared and shaking a lot. I was sweating. People were staring at me. A kid said, "What the fuck?" I said "thank you" in response. Another kid called me a "faggot." I felt angry.

One TGD youth described a caregiver's negative response to their use of nail polish, which subsequently impacted their gender expression:

When I first came out, my dad started screaming. He said painting my nails was a horrible thing. With Dad, I feel like I have to present as more masculine. He made me feel like I had to hide my identity. I felt like giving up and going along with it, but not anymore.

Another participant highlighted repeated caregiver verbal abuse regarding their gender expression, which exacerbated their feelings of gender dysphoria (i.e., discomfort associated with the incongruence between one's gender and birth-assigned sex; Coleman et al., 2012) and suicidal ideation:

My mom made me wear a lot of dresses and skirts. She guilted me into wearing them. One time, I wore jeans with a skirt. She got mad and would yell at me for not being ladylike. I felt trapped. She has made fun of my binding and boobs. She tells me it's weird that I want to hide and chop off my breasts. My chest is the biggest thing I get dysphoric about. My mind goes to thoughts of suicide from Mom saying hateful things. TGD youth also experienced verbal abuse when adults (e.g., caregivers, teachers) perceived their gender expression as not conforming to gender roles stereotypically associated with their birthassigned sex: 
My family uses a lot of stereotypes: gender roles and expression. Many years ago, my dad used to say, "Stop acting like a girl." I kept acting like one. He would say, "Stop! That's feminine.” I kept on being myself.

In response to a question about suicidal ideation, one participant noted the distressing nature of such comments from a teacher in response to emotional expressions deemed inconsistent with their birth-assigned sex:

I thought about killing myself every day in sixth grade. My teacher was mean and scary and would scream at me for little things. I was always anxious and cried when my teacher yelled. My teacher told me to "man up" and "toughen up."

\section{Sexualization}

Verbal abuse served to sexualize TGD youth based on their gender (e.g., presuming TGD youth are sexually active or promiscuous). Multiple participants reported being called "slut," "skank," or "whore." While this form of verbal abuse is commonly inflicted upon birth-assigned girls, participants directly connected this to their TGD identity (e.g., in response to questions on traumatic experiences or school harassment related to gender presentation). In one case, a peer associated a TGD youth's expression of pride with sexual activity:

I socially transitioned one year ago in middle school. Some people don't accept this at

all. In class, boys are mean. While wearing a trans pride shirt on the bus, one boy said, "Having sex is a sin." I stopped sitting at the back of the bus.

Negative aspersions about TGD youth's presumed sexual activity (e.g., infidelity, incest) by peers was associated with significant distress, documented here in one participant's response to a question on self-harm: 
I found out that people from school were spreading rumors that I was cheating on my partner and having sex with my family members. My classmates claimed I was trans because I was molested by my father. I was angry around that time and started smashing stuff in the house, including a picture frame. I cut myself with one of the shards.

\section{Cyberbullying}

Cyberbullying, or electronically-communicated gender-related verbal abuse (e.g., via text message, on social media), was frequently reported by TGD youth. Though the nature of cyberbullying often overlapped with other subthemes (e.g., motivated by gender expression), its ubiquity warranted its own subtheme. Consistent with this notion, one participant shared:

The amount of harassment from people online is ridiculous. I came out as my affirmed name on Instagram. Within a couple minutes of posting, one person sent the message: "You're not a dude." Other people I don't know messaged me: "Do you have a penis or a vagina?"

Cyberbullying sometimes involved transphobic and homophobic comments:

A lot of my friend group is trans or nonbinary, but one guy is cis. He invited people from Discord (i.e., an online messaging platform) to play Minecraft (i.e., an online game).

They started calling me names. It was the first time I ever heard transphobic and homophobic remarks.

As indicated by one participant, cyberbullying was a source of considerable distress:

A person I thought was a friend would make jokes. He said, "I have real balls." He would call me "it" over Facetime and ooVoo (i.e., a video chat platform). Once he said, "I don't know what you are. A person? You're the child called 'it."' I was crying and upset. 


\section{Gender-Related Physical and Sexual Assault: "If You Want To Be a Boy, I'll Hit You Like} One"

Threats and acts of gender-related physical (e.g., kicking, beating) and sexual (e.g., unwanted sexual touching, rape) assault were frequently reported.

\section{Threats of Physical Assault}

Several TGD youth reported threats of physical assault motivated by their gender. For one participant, this occurred shortly after they first presented as their affirmed gender at school. As demonstrated here and in the next quote, TGD youth reported that school personnel often failed to support them:

I cut my hair the summer before ninth grade and started wearing mostly boy clothes. I came out that year. No physical fights at school, but I got close when a football player said, "If you want to be a boy, I'll hit you like one." When bullied, I can't just turn the cheek, and I say something to defend myself. Then I get labeled as the aggressor. Other kids complained to the school administration that I was threatening and harassing others. One of the administrators said that I was lying when I tried to explain.

Other physical threats involved assault with a deadly weapon. In response to a question on trauma related to gender presentation, one participant shared:

When I was in elementary school, a kid from down the street bullied me. He threatened to bring a knife to school to kill me the next day. He didn't get into trouble. The principal didn't do anything.

TGD youth were also exposed to, or learned of, broader threats of violence against TGD people, which led to fear and avoidance: 
One time I did a panel at school. Someone said, "We should have mass genocide of all gay and trans people in America." People who heard this said they wouldn't report it. I didn't know who it was. I didn't know what to do. It made me scared to do another panel.

\section{Acts of Physical and Sexual Assault}

Physical assault was commonly enacted by peers, often in response to TGD youth's gender identity disclosure (i.e., "coming out") or gender expression.

I had a coming out day at school. I wore a trans pride flag and makeup. My ex-partner snapped and swung a Chromebook at my ass and thigh. I got a bruise and couldn't sit correctly.

Participants linked these assaults to serious emotional distress:

In fourth grade, kids saw me dressing like a boy and being "different." Both boys and girls bullied me. Girls spread rumors and called me names. Boys called me names. I would get beat up, and that's when I started cutting. Once, I got kicked, punched in the stomach, and shoved against a wall. My school didn’t do anything. My teacher saw and didn't care. My cutting started then, as soon as the physical bullying started.

TGD youth also reported experiences of gender-related sexual assault, which one participant connected with re-experiencing symptoms:

Last year, a girl at school was rude and impolite. She didn't understand boundaries. She would complain about her period and remind me that I didn't have one. She felt like it was her issue to promote body acceptance and got annoyed with me for being uncomfortable with my body. In bathrooms at school, she would touch me inappropriately to get me to be more comfortable with my body. No one knew: not 
school, staff, or parents. I would tell her to stop. It made me feel uncomfortable in my body and violated. I am reminded about it in bathrooms.

\section{Gender-Related Discrimination: "Wrong Locker Room"}

Gender-related discrimination was conceptualized as interpersonal acts and institutional policies restricting TGD youth from actualizing or expressing their gender.

\section{Names and/or Pronouns}

Many participants were prevented from changing their name and/or pronouns. This occurred most often in schools, where personnel and systems (e.g., email) were ill-equipped or failed to accommodate TGD youth:

When I got to high school, I made new friends and introduced myself using my affirmed name. I asked about changing my name and pronouns at school. The school said I should talk to my principal. Last year, I talked to the principal. On the school email system, my name and pronouns can't be changed.

This resulted in a teacher deadnaming another participant, who subsequently avoided using their affirmed name in their classroom:

Near the end of the year in math class, the substitute teacher said my deadname. I didn't respond to it. All the kids were silent because it was awkward for them. My school said they changed my name, but it didn't happen for that. I didn't say my affirmed name after that.

\section{Gender Expression}

Families frequently opposed TGD youth's gender expression, including their ability to dress in a manner consistent with their affirmed gender: 
If I could afford to, I would prefer to wear female clothing. I had conversations with my family about wanting female clothes or going shopping for them, but they shot me down. I asked my parents if I could have money for clothing. They refused to give me money to buy clothes to present myself as my affirmed gender.

Similarly, caregivers prohibited participants from modifying their appearance (e.g., hairstyle). As one TGD youth explained, this resulted in peer verbal abuse and emotional distress:

My mom pushes me to be stereotypically beautiful: stick thin and long, flowy hair. In seventh grade, I want a pixie cut. My mom said no. She said my hair was my best asset. Going into high school as a different gender was going to make my life harder. I wanted to cut my hair short. My mom told me I couldn't start high school with short hair because people would think I was an emo lesbian stoner. I had to start high school with long hair. People called me "faggot." It was a degrading feeling.

This same participant discussed the distress they experienced when their caregivers repeatedly prevented them from wearing a binder (i.e., an undergarment used to compress breasts):

I bought a binder my freshman year. My parents found out and took it away. They never gave it back to me. A friend bought one, and I wore that one. My parents found out and took it away, too. Another friend bought another. They took it away. It was heartbreaking.

\section{Physical Spaces}

TGD youth were denied access to physical spaces consistent with their gender, primarily school bathrooms and locker rooms. At times, this was enforced through verbal or physical assault by peers and resulted in future avoidance of these locations: 
Last year, in the locker room at school, a kid said "wrong locker room" and bullied me. I didn't go to gym for weeks. I haven't gone to the locker room since then.

In other instances, this was sanctioned by school policies or personnel (e.g., teachers, nurses, coaches):

I present as "she" and use the women's bathroom at school. But, this week I was at a hockey game. My teacher said I couldn't use the women's bathroom and that I'd have to use a unisex bathroom instead. But, because there wasn't one, I had to hold my urine.

As noted by one participant, the mere knowledge of similar experiences among TGD peers was distressing:

I get anxious and paranoid when I'm in the bathroom at school. I don't want to be harassed or teamed up on. It's happened to others. Some people have been slurred at and harassed. The school says they're supportive, but they don't pay that much attention.

\section{Gender-affirming Care}

Participants outlined ways in which caregivers delayed or restricted their access to gender-affirming care. For instance, a caregiver withheld access to a gender-affirming provider as a form of retribution against one participant:

I had an appointment with a doctor to talk about gender, but my mom canceled it after we had a huge fight. I was really upset, ran away from home, and stayed with my partner and their parents for the entire summer.

In a separate account, a participant's caregiver only permitted access to gender-affirming care after requiring them to change their appearance: 
Before we made an appointment (at a gender-affirming clinic), my mom made me get a haircut. She said, "I am not going to call to make an appointment until you get a haircut." After we made the appointment, we didn't talk about it for a long time. She thought I would be abused if I go with long hair. It felt like she was not taking care of me. Another TGD youth's caregiver refused to allow them to access gender-affirming care while living at home, despite advice from their therapist:

I asked my therapist about hormone therapy, who gave helpful tips and sent an email with helpful advice. My mom said I was not allowed in hormone replacement therapy. She said she didn't believe in it. This made me upset. I don't think Mom's changed. She wants me to get help and treatment, just not under her roof.

\section{Gender-Related Nonaffirmation: "What Are You?"}

Acts of gender-related nonaffirmation — with and without malicious intent—were extensively endorsed by participants and tied to psychological distress. This theme refers to ways in which others questioned, minimized, failed to acknowledge, or actively denied TGD youth's gender.

\section{Misgendering}

Misgendering comprised instances in which others referred to TGD youth's gender (e.g., use of pronouns) incorrectly (i.e., inconsistent with their affirmed gender). As emphasized by one participant, misgendering often followed identity disclosure and was upsetting:

When I first came out at home, my mom misgendered me a lot. It happened multiple times a week. I would cry myself to sleep.

Similar effects were endorsed by a participant who was misgendered by peers at school: 
I am harassed by peers sometimes, but I don't say anything. I am called "she" sometimes at school. When corrected by others, they deny it or forget what they said. They make excuses or pretend they didn't do anything wrong. It's obnoxious. I have a lot of anxiety and depression when misgendered.

Misgendering was sometimes persistent, causing one TGD youth to question their family's intentions:

I remind my family of how I identify. I remind them of my pronouns. I asked them to change pronouns to female two to three months ago. I have to remind them all the time. They are struggling to understand my identity. I question whether they forget or if they are unsupportive. I hear them using "he" with others and at home.

\section{Deadnaming}

Deadnaming captures the unwanted use of a TGD individual's birth name rather than their affirmed name, which multiple participants experienced and considered intentional:

I never had the best relationship with my dad, but it's gotten worse since I came out. He was never really on board with my gender transition. He has been trying to convince me that I'm wrong. Dad doesn't say my affirmed name. He says my full birth name to me as a form of retaliation. I feel free when he is away.

As with other gender-related adversities, deadnaming contributed to severe emotional distress:

At school, one kid in my class asked, "Who is [affirmed name]?" I said, "Me." They replied, "What, you don't want to be called [deadname] anymore?" I went into the bathroom and had a panic attack.

Gender Questioning, Minimizing, and Denial 
Families and peers questioned, minimized, and denied TGD youth's gender. For instance, one TGD youth's caregiver interrogated their gender during a routine medical procedure shortly after they came out and began changing their clothing preferences:

In eighth grade, I dressed feminine in an androgynous way: skinny jeans and a t-shirt. I felt good. On the day of the flu shot, my mom asked, "What are you?" She was mad because she wasn't sure how to explain being trans to others.

Another TGD youth relayed a similar experience instigated by fellow client in a mental health treatment program, which intensified their thoughts of suicide.

I started harming myself with a plastic knife and sharp objects at an intensive outpatient program. A girl there was bullying me and making scenes. She asked, "Are you a boy or a girl?” I was questioning myself. I just walked away crying and didn’t do anything. It made me worse and more suicidal.

At times, caregivers dismissed the permanency of TGD youth's gender by equating it to a phase or trend:

I came out on vacation. I overheard my parents tell my brother while I was taking a nap. My parents thought I was asleep. I remember hearing my dad say, "We hope that is going to change and it's a phase of life." A similar experience was echoed by another participant: My dad can be belittling. Instead of talking about things that I'm doing wrong, he'll make passive aggressive remarks. He thinks my gender is a phase and it's trendy. It's invalidating. He said that's the one thing he'll never approve of.

In several cases, family members denied TGD youth's gender entirely, permanently damaging relationships at times (for more examples, see also gender-related rejection): 
My mom has said, "You'll never be a man! I'm going to talk to my real son now." She says this more when stressed or frustrated. She doesn't see my gender as an urgent issue. The last time I saw my dad, he said my gender identity didn't matter. He said, “There are more important things in the world." I don't plan to talk to him the rest of my life.

Such repudiation was characterized as traumatic by one TGD youth:

I came out to my parents in the summer between eighth and ninth grade. I was confident in who I identified as. When I told my family, they said they'll love me unconditionally but refused to use my name and pronouns. In an argument, my dad said, "You will never be a boy." This was traumatic to hear from a parent. I didn't come out at school until the end of ninth grade. I was worried my parents would get upset. They weren't ready.

For others, denial of their gender induced feelings of anger:

Mom knew I was “different” from the start. She tried to stamp it out of me. She said, "You're not a boy. You're a girl." I also battle with my grandma. She said, "You're not a boy.” But, I feel like I am. I would get mad, frustrated, and pissed off.

Notably, as highlighted by one participant (and endorsed by others), TGD youth's distress was not intrinsic to gender but attributable to nonaffirmation by others:

My distress was worse when I came out. Mostly my mother's reaction to coming out. I wasn't uncomfortable with my identity. I was uncomfortable with my mom's reaction.

\section{Gender-Related Rejection: “I Don't Make Friends with Transgender People"}

Gender-related rejection involved instances in which participants were rejected by, or emotionally or physically distanced from, peers or family members because of their gender. We did not divide gender-related rejection into subthemes. Rather, quotes illustrate various 
manifestations of this theme across relationships (e.g., friends, families). For instance, one participant experienced rejection after disclosing their TGD identity to a friend:

I have no friends at school, just my teachers and social workers. People come up to me at school and ask, “Are you a boy or a girl?” When I say girl, they walk away and laugh. I'm shy and scared. My last friend was a girl back in sixth grade. She said, "I don't make friends with transgender people."

Another TGD youth felt emotionally distanced from their family, which was partly related to their caregivers' unwillingness to accept their gender:

My parents are distant due to a lot of reasons. Part of it is their lack of general acceptance of me, as they do not call me by my affirmed name and mispronoun me.

Family rejection also extended to physical separation from caregivers:

In eighth grade, my mom tried to keep me from wearing a binder. She told me it didn't look good. Last time I saw her on Thanksgiving three years ago, we got into a fight because I didn't want to wear a bra. My dysphoria was so bad that day. I was panicking. My mom was screaming at me because I was not wearing a bra. I wanted to wear a binder. She said, "Either wear a bra or go with Dad." I called my dad and said, "I need you to pick me up." I grabbed all my stuff, packed it up, and left. My mom never reached out again. I tried multiple times to contact her. She never responded.

\section{Discussion}

Our qualitative analysis of clinical interview data from TGD youth seeking genderaffirming care highlighted the ubiquity and negative emotional impact of gender-related adversities. Participants also endorsed widespread exposure to non-gender-related adversities. Consistent with extant literature (e.g., Schnarrs et al., 2019), our findings reflect a wide spectrum 
of traumatic and adverse experiences faced by TGD youth. The degree and complexity of adversity exposure documented in this study is particularly notable given that all participants were seeking gender-affirming care and thus those under 18 years old (93\% of the sample) had received caregiver consent to do so. In other words, our sample was comparatively privileged, as caregiver support for gender-affirming care is relatively limited among TGD youth (Andrzejewski et al., 2020). Yet, despite having at least one caregiver instrumentally supporting their gender-affirming care, participants still faced considerable gender-related adversity in multiple settings (e.g., school, home, public) and from multiple people in their lives (e.g., caregivers, friends, classmates, other adults). Five gender-related adversity themes emerged, and each included nuances unrecognized in existing measures of adversity (e.g., Expanded ACEs Scale; Karatekin \& Hill, 2019) and gender minority stress (e.g., GMSR measures; Hidalgo et al., 2019; Testa et al., 2015). Below, we highlight the convergence and divergence of our findings with the adversity constructs in these scales. We conclude with recommendations for both clinical assessment practices with TGD youth and the development of future adversity measures.

\section{Convergence and Divergence with Existing Measures}

The adversities captured in the current study overlap with several items on both the Expanded ACEs (Karatekin \& Hill, 2019) and GMSR (Hidalgo et al., 2019; Testa et al., 2015) measures. In other words, these measures strongly converged with many adversities in our data, providing further support for their utility with TGD youth. However, several facets of adversity specific to gender and childhood emerged that were not reflected in existing scales, including the recently-adapted GMSR measure for adolescents (Hidalgo et al., 2019).

Notably, all five gender-related themes we identified were characterized by emotional distress - a key outcome necessary for conceptualizing a trauma or adversity as an ACE (Felitti 
et al., 1998). For instance, neither the original nor the adolescent version of the GMSR measure adequately captured the range of settings (e.g., public, school) and interpersonal relationships (e.g., families, peers) in which participants frequently experienced discrimination or other adversities. Importantly, schools oftentimes exacerbated adversity for TGD youth. Specifically, several participants noted inadequate school support - either institutionally (e.g., mechanisms to support name change) or interpersonally (e.g., from teachers, principals)—when they faced victimization or other forms of adversity. Incorporating such experiences into adversity measures is important, given the centrality of schools in supporting the wellbeing and mental health of youth generally (Aldridge \& McChesney, 2018) and TGD youth specifically (Colvin et al., 2019).

Many of the gender-related adversities we identified highlighted TGD youth's distinct developmental experiences and were oftentimes more nuanced than existing Expanded ACEs and GMSR scale items (including those adapted for adolescents; see Hidalgo et al., 2019). For example, participants noted difficulties accessing affirming clothing, accessories (e.g., binders), and resources (e.g., gender-affirming care), which were often restricted by their caregivers. They also reported multidimensional (i.e., occurring in person and online) and multifaceted (i.e., relating to perceptions of gender roles, expressions, and sexuality) experiences of gender-related victimization, complexities not captured by either the Expanded ACEs Scale or GMSR measure. In addition, whereas the GMSR measure only inquires about bathroom access, our study and others (e.g., Jones et al., 2016; Murchison et al., 2019; Rosenberg, 2019) outline several other gendered spaces in which discrimination occurs (e.g., gyms, health class, locker rooms, playgrounds). Finally, several participants endorsed being told that their gender identity was a phase, which they described as highly distressing. Although this is consistent with other studies 
outlining the adverse mental health impact of this form of gender-related nonaffirmation (e.g., Johnson et al., 2020), we are not aware of its consideration in existing adversity measures.

\section{Recommendations for Measure Development Research}

First, we recommend that the Expanded ACEs Scale (Karatekin \& Hill, 2019) be adapted to include, at the very least, "gender" in the discrimination item. Second, as no existing measures (separately or together) sufficiently capture the depth and diversity of adversities experienced by TGD youth in our study, at least to our knowledge, we recommend that novel and comprehensive measures be created and validated for use in both research and clinical settings.

Scholars suggest that their development be informed by qualitative research elucidating phenomena targeted by an assessment, particularly if those phenomena are complex, such as identity-related adversity (Creswell \& Zhang, 2009; Stutterheim \& Ratcliffe, 2021). We believe that our study provides one such framework. Drawing on our findings, we recommend that novel measures of gender-related adversity more comprehensively address the following constructs: gender-related verbal abuse, physical and sexual assault, discrimination, nonaffirmation, and rejection. Among these five themes, nonaffirmation stood out as particularly common, multifaceted, and distressing, yet it was inadequately assessed for in existing measures. Questions specific to some of the most common forms of nonaffirmation, such as deadnaming, misgendering, and labeling TGD identity a "phase," should be included in future measures. Likewise, new measures should capture the novel and youth-specific themes and nuances highlighted in our results (e.g., the saliency of caregivers and schools). Finally, as participants experienced adversities not explicitly related to gender across a range of settings and sources, adversity measures for TGD youth (and youth generally) should utilize an expanded ACE framework (e.g., incorporating items from the Expanded ACEs Scale; Karatekin \& Hill, 2019). 


\section{Recommendations for Clinical Assessment and Practice}

Until comprehensive measures of gender- and non-gender related adversity are developed, we recommend that social workers and other mental health providers administer both the Expanded ACEs Scale (Karatekin \& Hill, 2019; or another comprehensive trauma or adversity scale or clinical interview) as well as the adapted GMSR measure for adolescents (Hidalgo et al., 2019) in clinical work with TGD youth. Comprehensively assessing adversity exposure is critical for (1) understanding the etiology of clients' mental health concerns, (2) assessing their risk for worsening or newly emerging psychological or behavioral difficulties (Vance \& Rosenthal, 2018), and (3) treatment planning (McCormick et al., 2018). These assessment practices may illustrate TGD youth's unique mental health needs and have important clinical implications. Indeed, our results highlighted the very distressing nature of gender-related adversities. For instance, experiences of nonaffirmation and rejection resulted in depression, anger, and self-harm, among other concerns, in our sample.

The addition of a TGD-specific adversity measure (e.g., the GMSR measure; Testa et al., 2015 ) in routine clinical assessment may also improve social work education, research, and training in gender-affirming practices — a need that has been identified elsewhere (e.g., Austin, Craig, et al., 2016) — simply by requiring clinicians to become familiar with its items and administration. Though much more work regarding the dissemination and implementation of gender-affirming training and practices for mental health providers is necessary (LelutiuWeinberger et al., 2016), enhancing the availability of routine measures may aid in these efforts. Further, our study, coupled with the wealth of literature on adversity exposure in TGD youth (e.g., Johns et al., 2019; Schnarrs et al., 2019), underscores the necessity of training in traumainformed care (i.e., practices that consider and integrate the complex nature of trauma, and its 
impact on clients, in assessment and treatment) for clinicians working with TGD youth (McCormick et al., 2018).

Though a comprehensive review of gender-affirming clinical practice is beyond the scope of the present study, we highlight a few key components that build upon the recommended assessment practices outlined above. First, it is important for social workers to clearly and overtly express a gender-affirming stance. This can be demonstrated in a multitude of ways, such as using gender inclusive language (i.e., language that avoids bias towards a specific gender and does not subscribe to the gender binary; e.g., allowing clients to write their gender on an intake form rather than providing specific categories) verbally and on all forms (e.g., intake forms, assessments, and clinical handouts), and displaying posters, brochures, and books embracing gender diversity (Austin, 2018).

Second, consistent with the National Association of Social Workers Code of Ethics, social workers should advocate for policies and practices that enhance the rights, wellbeing, and safety of their TGD clients (NASW, 2017). For example, if data from a comprehensive assessment of gender- and non-gender related adversity suggest that an institution (e.g., school) is exacerbating concerns (e.g., due to the absence of all-gender bathrooms), treatment may include advocacy work to reduce these barriers. Examples might include social workers asking institutions about their gender-affirming policies and practices, and helping clients advocate for change within these settings. Recognizing how institutions and supportive adults (e.g., teachers, caregivers) may or may not reduce or prevent adversity exposure in TGD youth is critical for mental health care providers serving TGD youth to understand and act on. Third, social workers should have readily-available resources for TGD youth and families. For example, social workers should be familiar with local gender-affirming medical providers to whom they can 
refer clients, and local, regional, or national organizations that provide guidance on enhancing supports in schools for TGD youth, and for parents of TGD youth (see Austin, 2018 for recommendations and resources for social work practice). In sum, gender-affirming social work practice should include comprehensive assessment and emphasize allyship and advocacy (Breaux \& Thyer, 2021).

\section{Strengths, Limitations, and Conclusions}

Our study has several strengths and limitations. First, our sample was large and diverse with respect to age, particularly for a qualitative study. However, participants were predominantly White and economically privileged (as suggested by access to private insurance for most participants), and all youth under 18 had at least one caregiver who was willing to provide consent for a gender-affirming care assessment. Future studies on adversity exposure in TGD youth will greatly benefit from recruiting more diverse samples, including TGD youth with other marginalized identities or experiences (e.g., youth of Color, low socioeconomic status, dearth of caregiver support). It will be particularly important for these studies to include racially and ethnically diverse samples of TGD youth, who may experience varying levels of acceptance and discrimination as well intersectional forms of adversity (Bradford et al., 2013; De Pedro et al., 2019; Hatchel \& Marx, 2018). Second, though we included several questions about genderand non-gender-related adversities — a strength of this study that distinguishes it from many others - our data were limited in their nature. Specifically, we analyzed assessors’ comprehensive notes, rather than verbatim transcripts from participants. Though this method has been found to produce rich results in other studies (e.g., Hojilla et al., 2016), future qualitative research should capture verbatim responses. 
Finally, our deductive analysis produced results with clear implications for clinical practice, including recommendations for the use of — and adaptations to - widely used measures of adversity and gender minority stress. Future studies might extend our findings by employing an inductive approach (wherein codes are derived directly from the data) to generate additional themes. Importantly, our results may be easily expanded upon in future measurement development studies, which we suggest be conducted using community-engaged research methods with the TGD community (Stutterheim \& Ratcliffe, 2021). Critically, executing these next steps in research may enhance clinical care for TGD youth by equipping clinicians with the tools necessary for adequately identifying and addressing factors associated with their enhanced risk for mental health problems. 


\section{References}

Adams, N., Pearce, R., Veale, J., Radix, A., Castro, D., Sarkar, A., \& Thom, K. C. (2017). Guidance and ethical considerations for undertaking transgender health research and institutional review boards adjudicating this research. Transgender Health, 2(1), 165175. https://doi.org/10.1089/trgh.2017.0012

Aldridge, J. M., \& McChesney, K. (2018). The relationships between school climate and adolescent mental health and wellbeing: A systematic literature review. International Journal of Educational Research, 88, 121-145. https://doi.org/10.1016/j.ijer.2018.01.012

Andrzejewski, J., Pampati, S., Steiner, R. J., Boyce, L., \& Johns, M. M. (2021). Perspectives of transgender youth on parental support: Qualitative findings from the resilience and transgender youth study. Health Education and Behavior, 48(1), 74-81. https://doi.org/10.1177/1090198120965504

Austin, A. (2018). Transgender and gender diverse children: Considerations for affirmative social work practice. Child and Adolescent Social Work Journal, 35(1), 73-84. https://doi.org/10.1007/s10560-017-0507-3

Austin, A., Craig, S. L., \& McInroy, L. B. (2016). Toward transgender affirmative social work education. Journal of Social Work Education, 52(3), 297-310. https://doi.org/10.1080/10437797.2016.1174637

Austin, A., Herrick, H., \& Proescholdbell, S. (2016). Adverse childhood experiences related to poor adult health among lesbian, gay, and bisexual individuals. American Journal of Public Health, 106(2), 314-320. https://doi.org/10.2105/AJPH.2015.302904

Becerra-Culqui, T. A., Liu, Y., Nash, R., Cromwell, L., Flanders, W. D., Getahun, D., Giammattei, S. V., Hunkeler, E. M., Lash, T. L., Millman, A., Quinn, V. P., Robinson, 
B., Roblin, D., Sandberg, D. E., Silverberg, M. J., Tangpricha, V., \& Goodman, M. (2018). Mental health of transgender and gender nonconforming youth compared with their peers. Pediatrics, 141(5):e20173845. https://doi.org/10.1542/peds.2017-3845

Benitez, M. (2010). Resituating culture centers within a social justice framework: Is there room for examining whiteness? In L. D. Patton (Ed.), Culture centers in higher education: Perspectives on identity, theory, and practice (pp. 119-134). Stylus Publishing, LLC.

Bockting, W. O., Miner, M. H., Swinburne Romine, R. E., Hamilton, A., \& Coleman, E. (2013). Stigma, mental health, and resilience in an online sample of the US transgender population. American Journal of Public Health, 103(5), 943-951. https://doi.org/10.2105/AJPH.2013.301241

Bond, M. A., Stone, A. L., Salcido, R., Jr., \& Schnarrs, P. W. (2021). How often were you traumatized? Reconceptualizing adverse childhood experiences for sexual and gender minorities. Journal of Affective Disorders, 282, 407-414. https://doi.org/10.1016/j.jad.2020.12.117

Bradford, J., Reisner, S. L., Honnold, J. A., \& Xavier, J. (2013). Experiences of transgenderrelated discrimination and implications for health: Results from the Virginia Transgender Health Initative Study. American Journal of Public Health, 103(10), 1820-1829. https://dx.doi.org/10.2105\%2FAJPH.2012.300796

Breaux, H. P., \& Thyer, B. A. (2021). Transgender theory for contemporary social work practice: A question of values and ethics. Journal of Social Work Values and Ethics, 18(1), 72-89. https://jswve.org/download/2021-1/2021-1-articles/72-Transgender-Theory-18-1-Spring2021-JSWVE.pdf 
Chang, T. K., \& Chung, Y. B. (2015). Transgender microaggressions: Complexity of the heterogeneity of transgender identities. Journal of LGBT Issues in Counseling, 9(3), 217234. https://doi.org/10.1080/15538605.2015.1068146

Clark, B. A., Veale, J. F., Townsend, M., Frohard-Dourlent, H., \& Saewyc, E. (2018). Nonbinary youth: Access to gender-affirming primary health care. International Journal of Transgenderism, 19(2), 158-169. https://doi.org/10.1080/15532739.2017.1394954

Coleman, E., Bockting, W., Botzer, M., Cohen-Kettenis, P., DeCuypere, G., Feldman, J., Fraser, L., Green, J., Knudson, G., Meyer, W. J., Monstrey, S., Adler, R. K., Brown, G. R., Devor, A. H., Ehrbar, R., Ettner, R., Eyler, E., Garofalo, R., Karasic, D. H., ... Zucker, K. (2012). Standards of care for the health of transsexual, transgender, and gendernonconforming people, version 7. International Journal of Transgenderism, 13(4), 165232. https://doi.org/10.1080/15532739.2011.700873

Colvin, S., Egan, J. E., \& Coulter, R. W. S. (2019). School climate \& sexual and gender minority adolescent mental health. Journal of Youth \& Adolescent, 48, 1938-1951. https://doi.org/10.1007/s10964-019-01108-w

Craig, S. L., Austin, A., Levenson, J., Leung, V. W. Y., Eaton, A. D., \& D’Souza, S. A. (2020). Frequencies and patterns of adverse childhood events in LGBTQ+ youth. Child Abuse \& Neglect, 107:104623. https://doi.org/10.1016/j.chiabu.2020.104623

Creswell, J. W., \& Zhang, W. (2009). The application of mixed methods designs to trauma research. Journal of Traumatic Stress, 22(6), 612-621. https://doi.org/10.1002/jts.20479 Cronholm, P. F., Forke, G. M., Wade, R., Bair-Merritt, M. H., Davis, M., Harkins-Schwarz, M., Pachter, L. M., \& Fein, J. A. (2015). Adverse childhood experiences: Expanding the 
concept of adversity. American Journal of Preventive Medicine, 49(3), 354-361. https://doi.org/10.1016/s0749-3797(98)00017-8

Cypress, B. S. (2017). Rigor or reliability and validity in qualitative research: Perspectives, strategies, reconceptualization, and recommendations. Dimensions of Critical Care Nursing, 36(4), 253-263. https://doi.org/10.1097/dcc.0000000000000253

Day, J. K., Perez-Brumer, A., \& Russell, S. T. (2018). Safe schools? Transgender youth's school experiences and perceptions of school climate. Journal of Youth and Adolescence, 47(8), 1731-1742. https://doi.org/10.1007/s10964-018-0866-x

De Pedro, K.T., Shim-Pelayo, H., \& Bishop, C. (2019). Exploring physical, nonphysical, and discrimination-based victimization among transgender youth in California public schools. International Journal of Bullying Prevention, 1, 218-226. https://doi.org/10.1007/s42380-019-00016-8

Ehrensaft, D., Hill, S., Johnson, J. L., \& Lahana, L. (2014). Gender-affirmative Mental Health Assessment Packet. [unpublished] Child and Adolescent Gender Center, University of California, San Francisco.

Elo, S., \& Kyngäs, H. (2008). The qualitative content analysis process. Journal of Advanced Nursing, 62(1), 107-115. https://doi.org/10.1111/j.1365-2648.2007.04569.x

Felitti, V. J., Anda, R. F., Nordenberg, D., Williamson, D. F., Spitz, A. M., Edwards, V., Koss, M. P., \& Marks, J. S. (1998). Relationship of childhood abuse and household dysfunction to many of the leading causes of death in adults: The Adverse Childhood Experiences (ACE) Study. American Journal of Preventive Medicine, 14(4), 245-258. https://doi.org/10.1016/S0749-3797(98)00017-8 
Finkelhor, D., Shattuck, A., Turner, H., \& Hamby, S. (2015). A revised inventory of Adverse Childhood Experiences. International Journal of Child Abuse and Neglect, 48, 13-21. https://doi.org/10.1016/j.chiabu.2015.07.011

Goldenberg, T., Jadwin-Cakmak, L., \& Harper, G. W. (2018). Intimate partner violence among transgender youth: Associations with intrapersonal and structural factors. Violence \& Gender, 5(1), 19-25. https://dx.doi.org/10.1089\%2Fvio.2017.0041

Grossman, A. H., D’Augelli, A., Howell, T. J., \& Hubbard, S. (2008). Parent' reactions to transgender youth' gender nonconforming expression and identity. Journal of Gay \& Lesbian Social Services, 18(1), 3-16. https://doi.org/10.1300/J041v18n01_02

Hatchel, T., \& Marx, R. (2018). Understanding intersectionality and resiliency among transgender adolescents: Exploring pathways among peer victimization, school belonging, and drug use. International Journal of Environmental Research and Public Health, 15(6):1289. https://doi.org/10.3390/ijerph15061289

Hidalgo, M. A., Petras, H., Chen, D., \& Chodzen, G. (2019). The Gender Minority Stress and Resilience Measure: Psychometric validity of an adolescent extension. Clinical Practice in Pediatric Psychology, 7(3), 278-290. https://dx.doi.org/10.1037\%2Fcpp0000297

Hill, C., Knox, S., Thompson, B. J., Williams, E. N., Hess, S., \& Ladany, N. (2005). Consensual qualitative research: An update. Journal of Counseling Psychology, 52(2), 196-205. https://doi.org/10.1037/0022-0167.52.2.196

Hill, C. E., Thompson, B. J., \& Williams, E. N. (1997). A guide to conducting consensual qualitative research. The Counseling Psychologist, 25(4), 517-572. https://doi.org/10.1177/0011000097254001

Hojilla, J. C., Koester, K. A., Cohen, S. E., Buchbinder, S., Ladzekpo, D., Matheson, T., \& Liu, 
A. Y. (2016). Sexual behavior, risk compensation, and HIV prevention strategies among participants in the San Francisco PrEP Demonstration Project: A qualitative analysis of counseling notes. AIDS and Behavior, 20(7), 1461-1469. https://doi.org/10.1007/s10461015-1055-5

Hwahng, S. J., \& Nuttbrock, L. (2014). Adolescent gender-related abuse, androphilia, and HIV risk among transfeminine people of Color in New York City. Journal of Homosexuality, 61(5), 691-713. https://doi.org/10.1080/00918369.2014.870439

International Federation of Social Workers. (2014, October 31). Sexual orientation and gender expression. IFSW. https://www.ifsw.org/sexual-orientation-and-gender-expression/

Johns, M. M., Lowry, R., Andrzejewski, J., Barrios, L. C., Demissie, Z., McManus, T., Rasberry, C. N., Robin, L., \& Underwood, J. M. (2019). Transgender identity and experiences of violence victimization, substance use, suicide risk, and sexual risk behaviors among high school students - 19 states and large urban school districts, 2017. MMWR. Morbidity and Mortality Weekly Report, 68. https://doi.org/10.15585/mmwr.mm6803a3

Johnson, K. C., LeBlanc, A. J., Deardoff, J., \& Bockting, W. O. (2020). Invalidation experiences among non-binary adolescents. Journal of Sex Research, 57(2), 222-233. https://doi.org/10.1080/00224499.2019.1608422

Jones, T., Smith, E., Ward, R., Dixon, J., Hillier, L., \& Mitchell, A. (2016). School experiences of transgender and gender diverse students in Australia. Sex Education, 16(2), 156-171. https://doi.org/10.1080/14681811.2015.1080678

Karatekin, C., \& Hill, M. (2019). Expanding the original definition of adverse childhood experiences (ACEs). Journal of Child \& Adolescent Trauma, 12, 289-306. https://doi.org/10.1007/s40653-018-0237-5 
Koita, K., Long, D., Hessler, D., Benson, M., Daley, K., Bucci, M., Thakur, N., \& Harris, N. B. (2018). Development and implementation of a pediatric adverse childhood experiences (ACEs) and other determinants of health questionnaire in the pediatric medical home: A pilot study. PLoS One, 13(12):e0208088. https://doi.org/10.1371/journal.pone.0208088

Kroppman, C., Kim, S., Zaidi, A., Sharma, H., \& Rice, T. R. (2021) Transgender and gendernonconforming youth deserve further study in relation to adverse childhood experiences. Journal of Gay and Lesbian Mental Health, 25(1), 2-4, https://doi.org/10.1080/19359705.2020.1837706

Kyngäs, H., \& Kaakinen, P. (2019). Deductive content analysis. In H. Kyngäs, K. Mikkonen, \& M. Kääriäinen (Eds.), The application of content analysis in nursing science research (pp. 23-30). Springer. https://doi.org/10.1007/978-3-030-30199-6

Lelutiu-Weinberger, C., Pollard-Thomas, P., Pagano, W., Levitt, N., Lopez, E. I., Golub, S. A., \& Radix, A. E. (2016). Implementation and evaluation of a pilot training to improve transgender competency among medical staff in an urban clinic. Transgender Health, 1(1), 45-53. https://doi.org/10.1089/trgh.2015.0009

Lincoln, Y. S., \& Guba, E. G. (1986). But is it rigorous? Trustworthiness and authenticity in naturalistic evaluation. New Directions for Program Evaluations, 30, 73-84. https://doi.org/10.1002/ev.1427

Meyer, I. H. (2003). Prejudice, social stress, and mental health in lesbian, gay, and bisexual populations: Conceptual issues and research evidence. Psychological Bulletin, 129(5), 674-697. https://doi.org/10.1037/0033-2909.129.5.674

McCormick, A., Scheyd, K., \& Terrazas, S. (2018). Trauma-informed care and LGBTQ youth: Considerations for advancing practice with youth with trauma experiences. The Journal 
of Contemporary Social Services, 99(2), 160-169.

https://doi.org/10.1177/1044389418768550

Murchison, G. R., Agénor, M., Reisner, S. L., \& Watson, R. J. (2019). School restroom and locker room restrictions and sexual assault risk among transgender youth. Pediatrics, 143(6):e20182902. https://doi.org/10.1542/peds.2018-2902

National Association of Social Workers. (2017). NASW code of ethics. NASW. https://www.socialworkers.org/About/Ethics/Code-of-Ethics/Code-of-Ethics-English

Nemoto, T., Bödeker, B., \& Iwamoto, M. (2011). Social support, exposure to violence and transphobia, and correlates of depression among male-to-female transgender women with a history of sex work. American Journal of Public Health, 101(10), 1980-1988. https://doi.org/10.2105/AJPH.2010.197285

Parr, N. J., \& Howe, B. G. (2019). Heterogeneity of transgender identity nonaffirmation microaggressions and their association with depression symptoms and suicidality among transgender persons. Psychology of Sexual Orientation and Gender Diversity, 6(4), 461474. https://doi.org/10.1037/sgd0000347

Peng, K., Zhu, X., \& Gillespie, A. (2019). Self-reported rates of abuse, neglect, and bullying experienced by transgender and gender-nonbinary adolescents in China. JAMA Network Open, 2(9):e1911058. https://dx.doi.org/10.1001\%2Fjamanetworkopen.2019.11058

Price-Feeney, M., Green, A. E., \& Dorison, S. (2020). Understanding the mental health of transgender and nonbinary youth. Journal of Adolescent Health, 66(6), 684-690. https://doi.org/10.1016/j.jadohealth.2019.11.314 
Pulice-Farrow, L., Brown, T. D., \& Galupo, M. P. (2017). Transgender microaggressions in the context of romantic relationships. Psychology of Sexual Orientation and Gender Diversity, 4(3), 362-373. https://doi.org/10.1037/sgd0000238

Pulice-Farrow, L., Clements, Z. A., \& Galupo, M. P. (2017). Patterns of transgender microaggressions in friendship: The role of gender identity. Psychology \& Sexuality, 8(3), 189-207. https://doi.org/10.1080/19419899.2017.1343745

Reisner, S. L., White Hughto, J. M., Gamarel, K. E., Keuroghlian, A. S., Mizock, L., \& Pachankis, J. (2016). Discriminatory experiences associated with posttraumatic stress disorder symptoms among TGD adults. Journal of Counseling Psychology, 63(5), 509519. https://doi.org/10.1037/cou0000143

Reisner, S. L., White, J. M., Bradford, J. B., \& Mimiaga, M. J. (2014). Transgender health disparities: Comparing full cohort and nested matched-pair study designs in a community health center. LGBT Health, 1(3), 177-184. https://doi.org/10.1089/1gbt.2014.0009

Riggs, D. W., Ansara, G. Y., \& Treharne, G. J. (2015). An evidence-based model for understanding the mental health experiences of transgender Australians. Australian Psychologist, 50(1), 32-39. https://doi.org/10.1111/ap.12088

Rosenberg, K. (2019). Higher prevalence of sexual assault among transgender and nonbinary adolescent students. American Journal of Nursing, 119(8), 49-50. https://doi.org/10.1097/01.naj.0000577444.69727.b0

Russell, S. T., Pollitt, A. M., Li, G., \& Grossman, A. H. (2018). Chosen name use is linked to reduced depressive symptoms, suicidal ideation, and suicidal behavior among transgender youth. Journal of Adolescent Health, 63(4), 503-505. https://doi.org/10.1016/j.jadohealth.2018.02.003 
Schnarrs, P. W., Stone, A. L., Salcido, R., Jr., Baldwin, A., Georgiou, C., \& Nemeroff, C. B. (2019). Differences in adverse childhood experiences (ACEs) and quality of physical and mental health between transgender and cisgender sexual minorities. Journal of Psychiatric Research, 119, 1-6. https://doi.org/10.1016/j.jpsychires.2019.09.001

Sterzing, P. R., Ratliff, G. A., Gartner, R. E., McGeough, B. L., \& Johnson, K. C. (2017). Social ecological correlates of polyvictimization among a national sample of transgender, genderqueer, and cisgender sexual minority adolescents. Child Abuse \& Neglect, 67, 112. https://doi.org/10.1016/j.chiabu.2017.02.017

Sotto-Santiago, S. (2019). Time to reconsider the word minority in academic medicine. Journal of Best Practices in Health Professions Diversity, 12(1), 72-78.

Stutterheim, S. E., \& Ratcliffe, S. E. (2021). Understanding and addressing stigma through qualitative research: Four reasons why we need qualitative studies. Stigma and Health, 6(1), 8-19. https://doi.org/10.1037/sah0000283

Tan, K. K. H., Treharne, G. J., Ellis, S. J., Schmidt, J. M., \& Vealfe, J. F. (2020). Gender minority stress: A critical review. Journal of Homosexuality, 67(10), 1471-1489. https://doi.org/10.1080/00918369.2019.1591789

Testa, R. J., Habarth, J., Peta, J., Balsam, K., \& Bockting, W. (2015). Development of the Gender Minority Stress and Resilience measure. Psychology of Sexual Orientation and Gender Diversity, 2(1), 65-77. http://dx.doi.org/10.1037/sgd0000081

Valentine, S. E., \& Shipherd, J. C. (2018). A systematic review of social stress and mental health among transgender and gender non-conforming people in the United States. Clinical Psychology Review, 66, 24-38. https://doi.org/10.1016/j.cpr.2018.03.003 
Vance, S. R., Jr., Ehrensaft, D., \& Rosenthal, S. M. (2014). Psychological and medical care of gender nonconforming youth. Pediatrics, 134(6), 1184-1192. https://doi.org/10.1542/peds.2014-0772

Vance, S. R., Jr., \& Rosenthal, S. M. (2018). A closer look at the psychosocial realities of LGBTQ youth. Pediatrics, 141(5):e20180361. https://doi.org/10.1542/peds.2018-0361

Veale, J. F., Peter, T., Travers, R., \& Saewyc, E. M. (2017). Enacted stigma, mental health, and protective factors among transgender youth in Canada. TGD Health, 2(1), 207-216. https://doi.org/10.1089/trgh.2017.0031

Wilson, E. C., Chen, Y., Arayasirikul, S., Raymond, H. F., \& McFarland, W. (2016). The impact of discrimination on the mental health of trans*female youth and the protective effect of parental support. AIDS and Behavior, 20(10), 2203-2211.

https://doi.org/10.1007/s10461-016-1409-7

Wirtz, A. L., Poteat, T. C., Malik, M., \& Glass, N. (2018). Gender-based violence against transgender people in the United States: A call for research and programming. Trauma, Violence, \& Abuse, 1-15. https://doi.org/10.1177/1524838018757749 


\section{Table 1}

Participant Demographic Information

\begin{tabular}{lc}
\hline Sample Demographics $(N=49)$ & \\
\hline Age & range: 11-20; $M(S D)=15.53(1.73)$ \\
\hline Race/ethnicity $(n)$ & 1 \\
African American & 1 \\
Asian & 8 \\
Latinx & 37 \\
Non-Hispanic or Unknown White & 2 \\
Non-Hispanic Other & 0 \\
Missing & 5 \\
\hline Self-identified gender expression $(n)$ & 44 \\
Nonbinary or gender nonconforming & 1 \\
Transgender & 1 \\
\hline Self-identified gender identity $(n)$ & 4 \\
Genderfluid & 9 \\
Genderqueer & 34 \\
Nonbinary & 35 \\
Transfemale & \\
Transmale & 11 \\
\hline Birth-assigned sex $(n)$ & 38 \\
Birth-assigned male & \\
Birth-assigned female & \\
\hline Insurance type $(n)$ & \\
Public (e.g., Medicaid) & \\
Military insurance & \\
Private & \\
\hline
\end{tabular}


Table 2

Trauma-related Interview Questions

\begin{tabular}{|c|c|}
\hline Category & Question \\
\hline $\begin{array}{l}\text { Adversity- } \\
\text { specific } \\
\text { questions }\end{array}$ & $\begin{array}{l}\text { Have you experienced or witnessed sexual, physical abuse, or emotional abuse? If } \\
\text { so, who committed the offense? What was the nature of the abuse (severity, } \\
\text { frequency, etc.)? What was the outcome? } \\
\text { Have you ever experienced a time when you did not have the food, clothes, or } \\
\text { shelter that you needed to survive? } \\
\text { Have you experienced community violence, previously? } \\
\text { Were you ever in a bad accident? What happened? } \\
\text { Has anyone close to you ever died unexpectedly? } \\
\text { Are there other losses or traumatic events that I did not ask you about? }\end{array}$ \\
\hline $\begin{array}{l}\text { Gender- } \\
\text { related } \\
\text { adversity } \\
\text { questions }\end{array}$ & $\begin{array}{l}\text { Are/were you ever harassed or ridiculed at home about your masculinity, } \\
\text { femininity, or ways you express your gender? Was/is there support at home for } \\
\text { your gender expression? } \\
\text { Describe any negative or traumatic experiences related to your gender } \\
\text { presentation. } \\
\text { At school, are/were you harassed or ridiculed because of your gender expression? }\end{array}$ \\
\hline $\begin{array}{l}\text { Other } \\
\text { adversity- } \\
\text { eliciting } \\
\text { questions }\end{array}$ & $\begin{array}{l}\text { Tell me about your caregivers, or anyone that has a significant role in your } \\
\text { upbringing. What is your relationship like with them? } \\
\text { Tell me about your siblings. What is your relationship like with each of them? } \\
\text { Has your family been supportive of your gender development, in particular, your } \\
\text { gender expressions? Describe positive and/or negative reactions as well as shifts } \\
\text { in family support over time. } \\
\text { How have your parents influenced your decision to present yourself as your } \\
\text { affirmed gender in different settings? Are there certain settings in which your } \\
\text { parents are more supportive of your affirmed gender presentation? What have } \\
\text { your discussions and/or plans with your parents been like regarding transitioning } \\
\text { in different settings? } \\
\text { Are you allowed by your parents to dress in the way that is most comfortable to } \\
\text { you? } \\
\text { Have you dressed in public as affirmed gender? What was that like? } \\
\text { To what extent has your gender identity been distressing over your lifetime? Has } \\
\text { it been more or less stressful at different times? } \\
\text { Is there support at school for your gender expression? Are you "out" to any } \\
\text { friends, teachers, administrators, etc. about your gender identity? What is their } \\
\text { current level of support? } \\
\text { What bathrooms/locker rooms do you currently use and what has this experience } \\
\text { been like? } \\
\text { Have you consulted with anyone else regarding your desire to transition? } \\
\text { What issues are problematic in your relationship (i.e., financial stress, substance } \\
\text { abuse, sexual issues)? } \\
\text { Are there friends or family members who oppose your desire to transition? How } \\
\text { do they express this opposition? }\end{array}$ \\
\hline
\end{tabular}


Outside of gender related issues, what are other major stressors you are currently dealing with?

Is there a history of medical or emotional concerns in your family?

Have you ever sought mental health treatment for any issue? If so, please describe the issues(s), location, provider, timing, duration, and outcome of the treatment(s).

Have you ever thought about killing yourself in the past?

How do you define your gender identity?

At what age did you feel as if you were of a different gender than the one you were assigned at birth? Describe what that was like for you.

If you attend a place of worship, what are your thoughts about disclosing (or not disclosing) your gender identity in that community?

Note. Interview questions taken from the "Gender-affirmative Mental Health Assessment Packet" (Ehrensaft et al., 2014). 
Table 3

Adversity Codebook Items, Definitions, and Associated Scales

\begin{tabular}{|c|c|c|}
\hline Code & Definition & Scale/Subscale \\
\hline $\begin{array}{l}\text { Gender-related } \\
\text { discrimination }^{\text {a }}\end{array}$ & $\begin{array}{l}\text { Youth experienced difficultly } \\
\text { accessing health care (including } \\
\text { gender-affirming care), public spaces } \\
\text { (e.g., bathrooms/locker rooms), and/or } \\
\text { other resources/opportunities because } \\
\text { of their gender. }\end{array}$ & $\begin{array}{l}\text { GMSR/gender- } \\
\text { related } \\
\text { discrimination }\end{array}$ \\
\hline Gender-related rejection $^{\mathrm{a}}$ & $\begin{array}{l}\text { Youth was rejected by or distanced } \\
\text { from family members, friends, and/or } \\
\text { peers because of their gender. }\end{array}$ & $\begin{array}{l}\text { GMSR/gender- } \\
\text { related rejection }\end{array}$ \\
\hline $\begin{array}{l}\text { Gender-related non- } \\
\text { affirmation }^{\text {a }}\end{array}$ & $\begin{array}{l}\text { Youth was misgendered, deadnamed, } \\
\text { and/or had their gender questioned, } \\
\text { minimized, or denied by others. }\end{array}$ & $\begin{array}{l}\text { GMSR/non- } \\
\text { affirmation of } \\
\text { gender identity }\end{array}$ \\
\hline Sexual abuse by grown-ups & $\begin{array}{l}\text { Adults (e.g., relatives, strangers) } \\
\text { touched youth's private parts, made } \\
\text { youth touch their private parts, and/or } \\
\text { forced youth to have sexual } \\
\text { intercourse. }\end{array}$ & $\begin{array}{l}\text { Expanded ACEs } \\
\text { /community } \\
\text { dysfunction }\end{array}$ \\
\hline Witnessing physical violence & $\begin{array}{l}\text { Youth witnessed someone (e.g., peers, } \\
\text { strangers) attacked with a weapon at } \\
\text { school or in public. }\end{array}$ & \\
\hline Burglary & $\begin{array}{l}\text { Youth stole item belonging to family } \\
\text { from house. }\end{array}$ & \\
\hline Forced sex by peers/siblings ${ }^{b}$ & $\begin{array}{l}\text { Peers, siblings, or partners forced } \\
\text { youth to have sexual intercourse. }\end{array}$ & \\
\hline $\begin{array}{l}\text { Imprisonment of parental } \\
\text { figure }\end{array}$ & Youth's caregiver went to prison. & \\
\hline Witnessing riots, etc. & $\begin{array}{l}\text { Youth directly saw or heard riots, } \\
\text { gunshots, or bombs exploding. }\end{array}$ & \\
\hline Witnessing war & $\begin{array}{l}\text { Youth witnessed war involving } \\
\text { fighting with guns or bombs. }\end{array}$ & \\
\hline Murder of someone close & $\begin{array}{l}\text { Youth knew someone close (e.g., } \\
\text { family member, friend) who was } \\
\text { murdered. }\end{array}$ & \\
\hline Parental figure going to war & $\begin{array}{l}\text { Youth's caregiver left home for } \\
\text { several months or longer to fight in } \\
\text { war. }\end{array}$ & \\
\hline Death of parental figure & Youth's caregiver died unexpectedly. & \\
\hline Witnessing murder & $\begin{array}{l}\text { Youth directly witnessed someone's } \\
\text { murder. }\end{array}$ & \\
\hline
\end{tabular}




\begin{tabular}{|c|c|c|}
\hline Physical bullying $^{\mathrm{b}}$ & $\begin{array}{l}\text { Youth was attacked by peers with an } \\
\text { object or weapon at school or in } \\
\text { public. }\end{array}$ & $\begin{array}{l}\text { Expanded } \\
\text { ACEs/difficulty with } \\
\text { peers/siblings and }\end{array}$ \\
\hline Threat of physical bullying ${ }^{b}$ & $\begin{array}{l}\text { Peers threated to physically hurt } \\
\text { vouth. }\end{array}$ & $\begin{array}{l}\text { property } \\
\text { victimization }\end{array}$ \\
\hline Name-calling ${ }^{\mathrm{b}}$ & $\begin{array}{l}\text { Peers called youth names or said mean } \\
\text { things. }\end{array}$ & \\
\hline $\begin{array}{l}\text { Physical attacks due to } \\
\text { discrimination }^{c}\end{array}$ & $\begin{array}{l}\text { Youth was physically attacked } \\
\text { because of race/ethnicity, immigration } \\
\text { status, disability, or sexual orientation. }\end{array}$ & \\
\hline Break/ruin things on purpose & $\begin{array}{l}\text { Youth intentionally broke or damaged } \\
\text { things. }\end{array}$ & \\
\hline Social isolation $^{\mathrm{c}}$ & $\begin{array}{l}\text { Youth experienced period of time with } \\
\text { no close friends. }\end{array}$ & \\
\hline Stealing & $\begin{array}{l}\text { Youth stole another person's property } \\
\text { (outside of home). }\end{array}$ & \\
\hline Stealing by force & $\begin{array}{l}\text { Others forcefully stole youth's } \\
\text { property. }\end{array}$ & \\
\hline Domestic violence at siblings & $\begin{array}{l}\text { Youth witnessed adult family } \\
\text { members physically hurt sibling(s). }\end{array}$ & $\begin{array}{l}\text { Expanded } \\
\text { ACEs/child }\end{array}$ \\
\hline Physical abuse ${ }^{\mathrm{b}}$ & Caregiver physically hurt youth. & maltreatment \\
\hline Physical neglect ${ }^{\mathrm{c}}$ & $\begin{array}{l}\text { Caregiver did not take care of youth } \\
\text { (e.g., not providing food, medicine, or } \\
\text { shelter) }\end{array}$ & \\
\hline Verbal abuse ${ }^{b}$ & $\begin{array}{l}\text { Caregiver called youth names or said } \\
\text { mean things. }\end{array}$ & \\
\hline Physical domestic violence & $\begin{array}{l}\text { Youth witnessed an adult family } \\
\text { member physically attack another } \\
\text { adult family member. }\end{array}$ & \\
\hline Psychological neglect $^{\mathrm{c}}$ & $\begin{array}{l}\text { Youth did not feel loved by anyone in } \\
\text { family. }\end{array}$ & \\
\hline $\begin{array}{l}\text { Forced separation from } \\
\text { family }^{c}\end{array}$ & $\begin{array}{l}\text { Youth were sent or taken away from } \\
\text { family. }\end{array}$ & \\
\hline Perceived discrimination & $\begin{array}{l}\text { Youth felt discriminated against } \\
\text { because of race/ethnicity, disability, } \\
\text { sexual orientation, or immigration } \\
\text { status. }\end{array}$ & \\
\hline Verbal domestic abuse & $\begin{array}{l}\text { Youth witnessed an adult family } \\
\text { member argue with or yell at another } \\
\text { adult family member. }\end{array}$ & $\begin{array}{l}\text { Expanded } \\
\text { ACEs/household } \\
\text { dysfunction }\end{array}$ \\
\hline Family substance use & $\begin{array}{l}\text { Youth's caregiver drank alcohol or } \\
\text { used drugs to excess. }\end{array}$ & \\
\hline $\begin{array}{l}\text { Divorce/ } \\
\text { separation of parents }\end{array}$ & $\begin{array}{l}\text { Youth's caregivers separated or } \\
\text { divorced. }\end{array}$ & \\
\hline
\end{tabular}


Family psychopathology $\quad$ Youth had family member who attempted suicide or was diagnosed with a psychiatric disorder.

Note. GMSR = Gender Minority Stress and Resilience measure (Testa et al., 2015). Expanded ACEs $=$ Expanded ACEs Scale (Karatekin \& Hill, 2019).

${ }^{a}$ Code taken from GMSR subscale and, by definition, comprised only gender-related adversity. ${ }^{b}$ Code adapted from the Expanded ACEs Scale, represents a form of victimization, and includes some gender-related adversity. As the Expanded ACEs Scale provides a more comprehensive assessment of victimization (compared to the gender-related victimization subscale of the GMSR), we used these items to inform victimization codes and documented both gender-related and non-gender-related victimization. ${ }^{\mathrm{c}}$ Code adapted from Expanded ACEs Scale but encompassed some gender-related adversity (i.e., some participants endorsed adversities consistent with this code that were specific to their gender). 
Table 4

Non-gender-related Adversity Themes and Subthemes with Example Quotes

Theme 1: Child Maltreatment

\begin{tabular}{|c|c|}
\hline Subtheme & Quote \\
\hline $\begin{array}{l}\text { Physical } \\
\text { abuse }\end{array}$ & $\begin{array}{l}\text { Have you experienced or witnessed sexual, physical abuse, or emotional } \\
\text { abuse? My dad hit me. I was } 16 . \text { He bruised my face and gave me a black } \\
\text { eye. He was charged with assault and disorderly conduct. } \\
\text { Have you experienced or witnessed sexual, physical abuse, or emotional } \\
\text { abuse? My biological mom has thrown things at me before. Once, she threw } \\
\text { a cup at me. Another time, she pinned me up against a wall and was } \\
\text { screaming at me. }\end{array}$ \\
\hline $\begin{array}{l}\text { Physical } \\
\text { neglect }\end{array}$ & $\begin{array}{l}\text { Have you ever experienced a time when you did not have the food, clothes, } \\
\text { or shelter that you needed to survive? I struggled with food before but } \\
\text { always found a way to eat. I didn't have water for a month because of pipe } \\
\text { issues. }\end{array}$ \\
\hline Verbal abuse & $\begin{array}{l}\text { When I was younger, my dad, without knowing he was doing it, made feel } \\
\text { like crap. He would pick on me for being lazy when I was going through a } \\
\text { hard time with depression and couldn't get out bed. He implied that I was } \\
\text { stupid and wasn't a good kid. There were lots of arguments and yelling in the } \\
\text { house. It has changed but affected me a lot. }\end{array}$ \\
\hline $\begin{array}{l}\text { Perceived } \\
\text { discrimination }\end{array}$ & $\begin{array}{l}\text { Outside of gender related issues, what are other major stressors you are } \\
\text { currently dealing with? A racist teacher yelled at me. }\end{array}$ \\
\hline $\begin{array}{l}\text { Psychological } \\
\text { neglect }\end{array}$ & $\begin{array}{l}\text { Have you experienced or witnessed sexual, physical abuse, or emotional } \\
\text { abuse? Most of my parents' attention was on my older brother or younger } \\
\text { brother. I wasn't paid attention to. My parents always relied on me to } \\
\text { function on my own. I learned how to care for myself very early on. I grew } \\
\text { up very quickly. It was always me caring for my mother, like I was her } \\
\text { therapist. She talked to me about pretty much everything. Now, I realize it } \\
\text { wasn't good at all. Looking back, it wasn't how kids should be raised. }\end{array}$ \\
\hline $\begin{array}{l}\text { Physical } \\
\text { domestic } \\
\text { violence }\end{array}$ & $\begin{array}{l}\text { Have you experienced or witnessed sexual, physical abuse, or emotional } \\
\text { abuse? I witnessed my biological dad beat and shove my mom. When I was } \\
\text { five months old, he pushed her so hard that I fell out of her arms. He did this } \\
\text { every time he came over. }\end{array}$ \\
\hline $\begin{array}{l}\text { Domestic } \\
\text { violence at } \\
\text { siblings }\end{array}$ & $\begin{array}{l}\text { My dad got violent with my older brother and hit him a couple times. In the } \\
\text { past, there was daily fighting between my older brother and parents. It was } \\
\text { scary, and I would hide in my room or closet. }\end{array}$ \\
\hline \multicolumn{2}{|r|}{ Theme 2: Community Dysfunction } \\
\hline $\begin{array}{l}\text { Sexual abuse } \\
\text { by grown ups }\end{array}$ & $\begin{array}{l}\text { Have you experienced or witnessed sexual, physical abuse, or emotional } \\
\text { abuse? My uncle was visiting when I was six. We were watching football on } \\
\text { TV. Then my memory blacks out. I remember my mom and my dad yelling } \\
\text { at him. My dad told me that I couldn't watch football with my uncle } \\
\text { anymore. Afterwards, my mom told me that they noticed something was } \\
\text { wrong when they heard me say, "Don't touch me there. That's my } \\
\text { underwear." }\end{array}$ \\
\hline
\end{tabular}


Forced sex by Have you experienced or witnessed sexual, physical abuse, or emotional peers/siblings abuse? My friend invited two guys over. I didn't feel comfortable with my body and didn't want to have sex with anybody. She had sex with her boyfriend, and she forced me to be in her sister's room. The other guy forced me to have sex with him. He's in the same grade as me, and I see him at school. We were close friends. He broke my heart.

Have you experienced or witnessed sexual, physical abuse, or emotional abuse? When I was nine, I was in the backyard next to the porch. My brother was asleep. The person who did it was someone who asked me out repeatedly, but I said I liked girls. He knew my address. He said he was going to come over. The abuse involved his hands and penis. I kicked, bit, and punched him and ran inside. I took a shower and threw my clothes in the trash. I only started talking about it last year. From nine to eleven, no one knew. He still harasses me on the bus, but my school won't do anything.

Witnessing Have you experienced community violence? I was in sixth grade during the physical violence Murder of someone Sandy Hook school shooting.

close

Imprisonment Dad was in jail for eight years. He kidnapped and attempted rape. I met with of parental figure my dad last year. It was weird being around him and overwhelming because I picked my affirmed name because it is gender neutral. My middle initial is for my friend's name. This is due to my friend's murder. I haven't seen him in over eight years. ${ }^{a}$ Theme 3: Difficulty with Peers and Siblings and Property Victimization

Physical bullying

Name calling, etc.
Have you experienced or witnessed sexual, physical abuse, or emotional abuse? This year, a girl kicked me over and over again. It was funny for her. She kicked me so hard that she made me fall. I started crying and went to the head teacher. She got in trouble and never did it again.

What is your relationship like with caregivers? Throughout my life, I've been distant with my mom. There are points where things have been really bad between us. There were many arguments where I would leave the house for days on end. I went to stay with friends or walked around town. We fought because "I wouldn't listen to her." The biggest fight involved having my big brother hit me, and my sister tried to choke me because my mom was getting stressed.

Have you experienced or witnessed sexual, physical abuse, or emotional abuse? When I was four, my brother would get angry and hit me. Sometimes there were bruises. Mom would yell at him, but he didn't care and would do it again. I remember at least one time he pushed me to the floor pretty hard.

Have you experienced or witnessed sexual, physical abuse, or emotional abuse? Once we broke up, my ex-partner started bullying and harassing me. They posted on Instagram and called my current partner a slut.

Have you experienced or witnessed sexual, physical abuse, or emotional abuse? I dated a girl. She would get drunk and call and text me saying that no one would love me and no one cared. She called me names and made me feel bad about myself. 


$\begin{array}{ll}\text { Social } & \text { Have you experienced or witnessed sexual, physical abuse, or emotional } \\ \text { isolation } & \text { abuse? In sixth grade, my best friend since third grade spent a lot of time } \\ \text { degrading me. This was the start of my struggle making relationships and } \\ \text { feeling close to people. } \\ \text { I started feeling a lot more depressed and cutting myself at age eleven. I felt } \\ \text { like nobody liked me, wanted to be around me, or wanted to be my friend. }\end{array}$

\begin{tabular}{|c|c|}
\hline $\begin{array}{l}\text { Verbal } \\
\text { domestic } \\
\text { violence }\end{array}$ & $\begin{array}{l}\text { Verbal fighting between parents as long as I remember. They were } \\
\text { screaming late at night every two or three weeks. They would argue about } \\
\text { sex. When I was in fifth grade, they had a fight at a campground at night. } \\
\text { They screamed at each other for three hours. Profanity and everything. } \\
\text { Dad was violent. He was never physically abusive but mostly yelled at my } \\
\text { mom. When I was a young child, it happened pretty often. It was part of } \\
\text { what led to parents' divorce. }\end{array}$ \\
\hline $\begin{array}{l}\text { Divorce/ } \\
\text { separation of } \\
\text { parents }\end{array}$ & $\begin{array}{l}\text { Are there other losses or traumatic events that I did not ask you about? My } \\
\text { dad moved out of the house within a week of telling me about parents' } \\
\text { divorce. I remember crying to my mom afterwards. I worried she was going } \\
\text { to leave too. Now, I have to worry about people leaving me. }\end{array}$ \\
\hline $\begin{array}{l}\text { Family } \\
\text { psycho- } \\
\text { pathology }\end{array}$ & $\begin{array}{l}\text { Is there a history of medical or emotional concerns in your family? There is } \\
\text { a history of depression in every family member. My maternal grandmother } \\
\text { attempted suicide five to ten times, and my dad attempted suicide at least } \\
\text { twice. }\end{array}$ \\
\hline & $\begin{array}{l}\text { Are there other losses or traumatic events that I did not ask you about? } \\
\text { When my sister was experiencing mental health problems, I felt like I was } \\
\text { being ignored by parents. I didn't feel that great, but I knew it wasn't on } \\
\text { purpose. They were just worried about her because so much was going on. } \\
\text { My sister had mental health issues for most of my life, but her } \\
\text { hospitalizations started when she was in eighth grade and I was in third } \\
\text { grade. My parents explained that her hospitalizations were due to mental } \\
\text { health. Most were for attempted suicide or thoughts of suicide. }\end{array}$ \\
\hline Family & Is there a history of medical or emotional concerns in your family? \\
\hline $\begin{array}{l}\text { substance } \\
\text { abuse }\end{array}$ & $\begin{array}{l}\text { Substance abuse by my dad: drinking and cocaine. My mom drinks a lot, too. } \\
\text { She says she drinks even when she doesn't want to because it's her only way } \\
\text { to cope. When I was five, I remember my parents got drunk at a party and } \\
\text { were puking on each other in the bathroom. Dad was arrested for driving } \\
\text { drunk. }\end{array}$ \\
\hline $\begin{array}{l}\text { Forced } \\
\text { separation } \\
\text { from family }\end{array}$ & $\begin{array}{l}\text { Dad was in jail for eight years. He kidnapped and attempted rape. I met with } \\
\text { my dad last year. It was weird being around him and overwhelming because } \\
\text { I haven't seen him in over eight years. }\end{array}$ \\
\hline
\end{tabular}

Note. Non-gender-related adversity themes correspond to ACE categories from the Expanded ACEs Scale (Karatekin \& Hill, 2019), and subthemes reflect Expanded ACEs Scale items. Expanded ACEs Scale (Karatekin \& Hill, 2019) items not endorsed by our sample included "burglary," "witnessing riots etc.," "parental figure going to war," "witnessing war," "witnessing murder," "break/ruin things on purpose," "stealing," and "stealing by force." The only instances of "threat of physical bullying," "physical attacks due to discrimination," and "forced separation 
from family" were explicit to gender and captured by codes derived from the Gender Minority Stress and Resilience (GMSR) measure (Testa et al., 2015).

aDouble coded as "imprisonment of a parental figure" and "forced separation from family."

bAlso coded as "name-calling, etc.". 